at New Jersey led the CIE by several thousands of years (but lagged the onset of the Apectodinium acme) (Sluijs et al., 2007b). This indicates that warm SST was not the only environmental control on Apectodinium abundances. Moreover, it suggests that the carbon burp that caused the CIE was a result of initial climate change and acted as a positive feedback. This scenario fits the model that $\mathrm{CH}_{4}$ release from submarine hydrates caused the CIE (Dickens et al., 1995). If this pre-CIE warming was global, it was likely induced by greenhouse forcing, suggesting that the PETM warming and ocean acidification were caused by at least two sources of carbon (Sluijs et al., 2007b).

\section{Concluding remarks}

The past years of research on the PETM and the more recently discovered additional hyperthermals have resulted in a clearer picture of these critical phases in Earth's history. Improved drilling techniques (Integrated Ocean Drilling Program) have resulted in the recovery of complete sections, and new analytical techniques have contributed to much better quantitative estimates of SSTs. Moreover, high-resolution studies on expanded marginal marine sequences have identified leads and lags in the interaction between the climate system and the carbon cycle during the onset of the PETM. The new data provide fundamental constraints for modeling global climate and carbon cycling, and are increasingly leading to an improved description and understanding of the state and dynamics of a (in this case the early Paleogene) greenhouse world.

\section{Acknowledgements}

I thank the Netherlands Organisation for Scientific Research for funding (VENI grant 863.07.001) and for their continued support of the Integrated Ocean Drilling Program. I also thank all my 'hyperthermal' colleagues, amongst others Stefan Schouten, Jim Zachos, Jerry Dickens, Ursula Röhl, Lucas Lourens, Jaap Sinninghe Damsté, Gert-Jan Reichart, Matt Huber, Gabe Bowen, Mark Pagani, Ellen Thomas, Dick Kroon, Cedric John, Steven Bohaty and Henk Brinkhuis for discussions over the past years.

\section{References}

Lourens, L.J., Sluijs, A., Kroon, D., Zachos, J.C., Thomas, E., Röhl, U., Bowles, J. and Raffi, I., 2005: Astronomical pacing of late Palaeocene to early Eocene global warming events, Nature, 435(7045): 1083-1087.

Sluijs, A. Schouten, S., Pagani, M., Woltering, M., Brinkjuis, H., Sinninghe Damsté, J.S., Dickens, G.R., Huber, M., Reichart, G.-J., Stein, R., Matthiessen, J., Lourens, L.J., Pedentchouk, N., Backman, J., Moran, K. and the Expedition 302 Scientists, 2006: Subtropical Arctic Ocean temperatures during the Palaeocene/Eocene thermal maximum, Nature, 441(7093): 610-613.

Sluijs, A., Bowen, G.J., Brinkhuis, H., Lourens, L.J. and Thomas, E., 2007a: The Palaeocene-Eocene thermal maximum super greenhouse: biotic and geochemical signatures, age models and mechanisms of global change. In: M. Williams, et al. (Eds), Deep time perspectives on Climate Change: Marrying the Signal from Computer Models and Biological Proxies. The Micropalaeontological Society, Special Publications, The Geological Society, London, pp. 323-349.

Sluijs, A., Brinkhuis, H., Schouten, S., Bohaty, S.M., John, C.M., Zachos, J.C., Sinninghe Damsté, J.S., Crouch, E.M. and Dickens, G.R., 2007b: Environmental precursors to rapid light carbon injection at the Paleocene/Eocene boundary, Nature, 450: 1218-1221.

Zachos, J.C. Röhl, U., Schellenberg, S.A., Sluiis, A., Hodell, D.A., Kelly, D.C., Thomas, E., Nicolo, M., Raffi, l., Lourens, L.J., McCarren, H. and Kroon, D., 2005: Rapid Acidification of the Ocean during the Paleocene-Eocene Thermal Maximum, Science, 308(5728): $1611-1615$

For full references please consult:

www.pages-igbp.org/products/newsletter/ref2008_1.htm

\title{
Pleistocene records of marine carbonate chemistry
}

\author{
Bärbel HönISCH ${ }^{1}$, J. Yu ${ }^{2}$ and N.G. Hemming ${ }^{3}$ \\ 'Lamont-Doherty Earth Observatory, Palisades, USA; hoenisch@ldeo.columbia.edu \\ ${ }^{2}$ Cambridge University, UK \\ ${ }^{3}$ Queens College, Flushing, USA
}

Ice core records provide the only direct archive for past atmospheric gas composition, and records spanning the past 670 kyr BP reveal a tight correlation between surface temperatures and atmospheric $\mathrm{pCO}_{2}$ (Petit et al., 1999; Siegenthaler et al., 2005). However, what determines the glacial and interglacial $\mathrm{pCO}_{2}$ extremes (i.e., 280 vs. 200 ppm), and where the $\mathrm{CO}_{2}$ was stored is poorly understood, although it is clear that the ocean is the only reservoir that could have absorbed the missing $\mathrm{CO}_{2}$ from the atmosphere (Broecker, 1982). This uncertainty hampers the prediction of future climate change with continued anthropogenic release of $\mathrm{CO}_{2}$, and there is a pressing need to better understand the interplay between atmospheric $\mathrm{pCO}_{2}$ and the much larger oceanic carbon reservoir.

There are several proxies for reconstructing marine carbonate chemistry, all of which have limitations (see Hönisch and Hall, 2007). Although the uncertainties may be large, multiproxy approaches for the late Pleistocene yield an increasingly consistent picture. Paleoreconstructions focus on two approaches: (1) To study the sensitivity of climate to greenhouse gas concentrations beyond the limit of ice coring in Antarctica, reconstructions have fo- cused on the past 60 Myr BP (Pagani et al., 1999, 2005; Pearson and Palmer, 2000; Royer et al., 2001). During this period, oxygen and carbon isotope records from benthic foraminifers indicate large climate fluctuations that coincide with perturbations of the carbon cycle (Zachos et al., 2001). (2) To quantify the potential of the ocean as a sink for $\mathrm{CO}_{2}$, carbonate chemistry reconstructions focus on benthic foraminifers (Marchitto et al., 2005; Sanyal et al., 1995; Yu and Elderfield, 2007). The glacial deep ocean is thought to be the largest carbon reservoir.

\section{Surface seawater carbonate chemistry}

As $\mathrm{CO}_{2}$ is well mixed in the atmosphere and is exchanged at the air-sea interface, knowledge of past sea surface carbonate chemistry can place constraints on past atmospheric $\mathrm{pCO}_{2}$. Boron isotopic compositions $\left(\delta^{11} \mathrm{~B}\right)$ in marine carbonates record past seawater $\mathrm{pH}$ (Hemming and Hanson, 1992; Hönisch et al., 2004; Reynaud et al., 2004; Sanyal et al., 1996, 2000, 2001). Laboratory and sediment validation studies have investigated vital shell size and dissolution effects on $\delta^{11} B$ of planktic foraminifers and corals. Symbiont photo- synthesis sequesters $\mathrm{CO}_{2}$ and thereby increases $\mathrm{pH}$ in the calcifying environment of foraminifers (Jørgensen et al., 1985; Rink et al., 1998) and corals (Al-Horani et al., 2003). Respiration has the opposite effect. In planktic foraminifers, these effects have significant consequences for the recorded pH (Hönisch et al., 2003). As symbiont-bearing foraminifers appear to grow larger under higher light levels (Spero and Lea, 1993), higher $\delta^{11} \mathrm{~B}$ of larger shells of the symbiont-bearing foraminifer Globigerinoides sacculifer is interpreted to reflect a shallower growth habitat (Hönisch and Hemming, 2004). The largest shells record surface seawater $\mathrm{pH}$, and because these shells are also the least susceptible to dissolution (typically resulting in offsets to lighter isotopic values), Hönisch and Hemming (2004) recommend using large shells for paleoreconstructions.

A 400-kyr record of $\delta^{11} \mathrm{~B}$ in large $G$. sacculifer shells from an open ocean sediment core in the equatorial Atlantic shows a 0.18 unit higher glacial ocean $\mathrm{pH}$ compared to interglacials (Hönisch and Hemming, 2005). This is consistent with previous results for Pacific and Atlantic surface seawater pH (Sanyal et al., 1995). Corresponding aqueous $\mathrm{PCO}_{2}$ estimations 
showed a remarkable match with the Vostok $\mathrm{pCO}_{2}$ record (Fig. 1; Hönisch and Hemming, 2005). Hönisch and Hemming are now in the process of extending the surface ocean $\mathrm{pH}$ records into the early Pleistocene and eventually throughout the Cenozoic. There are several problems to overcome in this endeavor, including uncertainty of the boron isotopic composition of seawater on time scales longer than 3-5 Myr BP (Lemarchand et al., 2000), unknown species effects, and the need to estimate surface ocean alkalinity or another parameter of the carbon system in addition to $\mathrm{pH}$ when estimating $\mathrm{PCO}_{2}$.

Carbonate chemistry in reef environments changes seasonally with both the productivity of the ecosystem and changes in the currents that carry the open ocean chemistry to the reef. Therefore, since $\delta^{11} \mathrm{~B}$ in corals reflect local conditions, corals are not suitable archives for approximating global atmospheric $\mathrm{pCO}_{2}$ (Hönisch et al., 2004; Pelejero et al., 2005).

Foraminiferal $\mathrm{B} / \mathrm{Ca}$ ratios have been proposed to reconstruct surface seawater $\mathrm{pH}$ (Yu et al., 2007). Similar to the boron isotope proxy, $\mathrm{B} / \mathrm{Ca}$ is based on the equilibrium reaction between boric acid and borate in seawater. Boron isotope studies suggest that borate is the species incorporated into marine carbonates, and the seawater borate concentration increases with $\mathrm{pH}$. A pilot study suggests that $\mathrm{B} /$ $\mathrm{Ca}$ is strongly dependent on calcification temperature, which could be corrected using $\mathrm{Mg} / \mathrm{Ca}$ temperature estimates. Application to the paleo-ocean yields a very promising result: $\mathrm{pH}$ of the last glacial Southern Ocean was estimated to have been 0.15 units higher and $\mathrm{PCO}_{2}$ was correspondingly $95 \mu \mathrm{atm}$ lower than during the Holocene (Yu et al., 2007). This is an exciting new approach that may allow for a much faster sample throughput. However, because carbonate chemistry and temperature in the ocean typically change in unison, culture experiments under controlled conditions in the laboratory are planned to better quantify the effects of $\mathrm{pH}$, temperature, salinity and boron concentration on $\mathrm{B} / \mathrm{Ca}$ in planktic foraminifers.

\section{Deepwater $\left[\mathrm{CO}_{3}{ }^{2-}\right]$}

The first boron isotope study to estimate glacial deep-sea pH used mixed benthic foraminifers and suggested a 0.3 units higher glacial pH in the Pacific and Atlantic oceans (Sanyal et al., 1995). This large $\mathrm{pH}$ change translates into a $100 \mu \mathrm{mol} \mathrm{kg}{ }^{-1}$ higher deepwater $\left[\mathrm{CO}_{3}{ }^{2-}\right]$, which is inconsistent with sediment records of carbonate preservation. More recent geochemical estimates use benthic foraminiferal

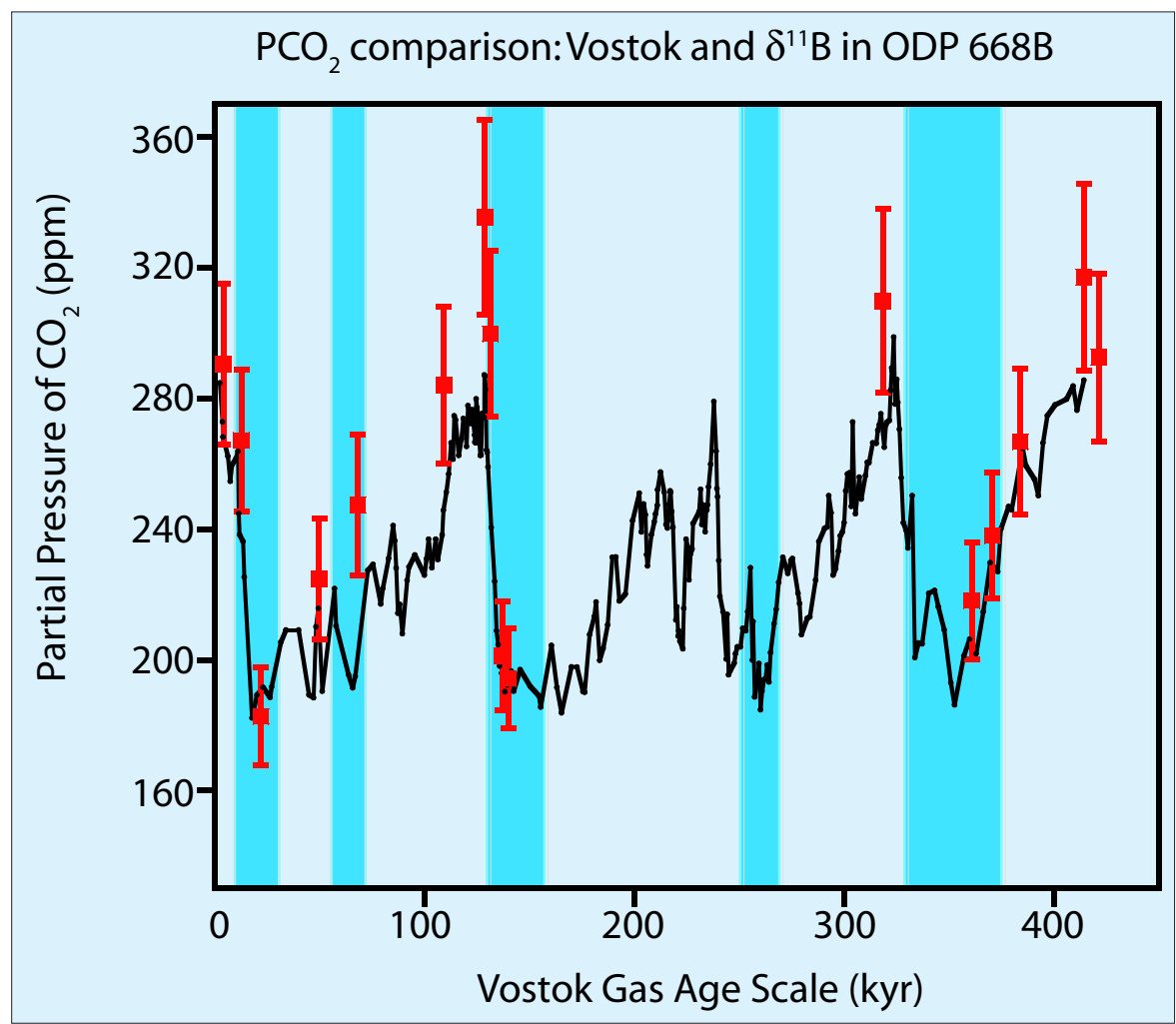

Figure 1: Estimated aqueous $\mathrm{PCO}_{2}$ from boron isotopes in planktic foraminifera (red squares) closely matches atmospheric $\mathrm{CCO}_{2}$ from the Vostok ice core record (black line), and indicates that atmospheric $\mathrm{CO}_{2}$ can be estimated from marine proxy records. Blue bars indicate glacial intervals. Modified from Hönisch and Hemming, 2005.

$\mathrm{Zn} / \mathrm{Ca}$ and $\mathrm{Cd} / \mathrm{Ca}$ (Marchitto et al., 2002), and $\mathrm{B} / \mathrm{Ca}$ ratios (Yu and Elderfield, 2007), which appear to be related to deepwater carbonate saturation state, although the exact mechanism of the respective relationship is not understood. Reconstructions of $\left[\mathrm{CO}_{3}{ }^{2-}\right]$ of the glacial Atlantic was 15-30 $\mu \mathrm{mol} \mathrm{kg}{ }^{-1}$ higher at intermediate depths, and $\sim 10-20 \mu \mathrm{mol} \mathrm{kg} \mathrm{kg}^{-1}$ lower in waters below the modern lysocline (water depth where the rate of calcite dissolution increases dramatically) (Farrell and Prell, 1989; Marchitto et al., 2002; Yu and Elderfield, 2007). In the Pacific Ocean, a $5 \mu \mathrm{mol}$ $\mathrm{kg}^{-1}$ increase occurred in waters deeper than $3000 \mathrm{~m}$ (Anderson and Archer, 2002).

Because of the large discrepancy between mixed benthic $\delta^{11} \mathrm{~B}$ data and other reconstructions, Hönisch, et al. (in prep.) measured $\delta^{11} B$ in single benthic foraminifer species, which yield corresponding $\left[\mathrm{CO}_{3}^{2-}\right]$ data that show a small glacial increase above the modern lysocline and a small decrease below the lysocline. This brings the boron isotope data in line with other reconstructions and strengthens the view that the deep ocean cannot have stored the entire missing $\mathrm{CO}_{2}$ in dissolved form. Biological mechanisms must have played an important role as well.

\section{Where to next?}

Beyond the need for detailed and faithful estimates of surface seawater $\mathrm{PCO}_{2}$ and atmospheric $\mathrm{pCO}_{2}$ throughout the Cenozoic (see above), detailed maps of deep sea carbonate parameters are needed to better quantify the past oceanic carbon reservoir. Particularly for deep-sea reconstructions, the mechanisms of the proxy relationships need to be studied and better calibrated, preferably in laboratory culture. Depth profiles from different locations in all ocean basins (particularly the Pacific and Southern Ocean) need to be generated, as well as reconstructions through longer periods of time at single locations. This is a long-term endeavor that needs to be approached by the entire paleoceanographic community and not just by single individuals.

\section{References}

Hönisch, B. and Hemming, N.G., 2004: Ground-truthing the boron isotope paleo-pH proxy in planktonic foraminifera shells: Partial dissolution and shell size effects, Paleoceanography, 19: doi:10.1029/2004PA001026.

Hönisch, B. and Hemming, N.G., 2005: Surface ocean pH response to variations in $\mathrm{pCO}_{2}$ through two full glacial cycles, Earth and Planetary Science Letters, 236: 305-314.

Hönisch, B., Hemming, N.G., Grottoli, A.G., Amat, A., Hanson, G.N. and Bijma, J., 2004: Assessing scleractinian corals as recorders for paleo-pH: Empirical calibration and vital effects, Geochimica et Cosmochimica Acta, 68: 3675-3685.

Yu, J. and Elderfield, H., 2007: Benthic foraminiferal B/Ca ratios reflect deep water carbonate saturation state, Earth and Planetary Science Letters, 258: 73-86.

Yu, J., Elderfield, H. and Hönisch, B., 2007: B/Ca in planktonic foraminifera as a proxy for surface seawater pH, Paleoceanography, 22 doi: 10.1029/2006PA001347.

For full references please consult: www.pages-igbp.org/products/newsletter/ref2008_1.html 